\title{
Characterization of phenolic profile alterations in metal-polluted bee pollen via capillary electrophoresis
}

Enrique Mejías1,2, Carlos J. Gómez3, Pierre Gareil4,5, Nathalie Delaunay4,5, and Gloria Montenegro6

1Universidad Tecnológica Metropolitana UTEM, Vicerrectoría Académica, Dirección de Investigación y Desarrollo Académico. Santiago, Chile.

2Universidad Tecnológica Metropolitana, UTEM, Facultad de Ciencias Naturales Matemática y Medio Ambiente, Departamento de Biotecnología. Santiago, Chile.

3Technical Governance, Metals \& Minerals, Bureau Veritas Chile. Santiago, Chile

4Chimie ParisTech, Physicochemistry of Electrolytes, Colloids \& Analytical Sciences. Paris, France.

5Centre National de la Recherche Scientifique (CNRS), Unités Mixtes de Recherche (UMR) 7195. Paris, France

6Pontificia Universidad Católica de Chile, Facultad de Agronomía e Ingeniería Forestal, Departamento de Ciencias Vegetales. Santiago, Chile

\begin{abstract}
Bee pollen is a conglomerate of plant pollens, and its nutritional contents include bioactive compounds with antioxidant/antiradical potentials. These potentials are conditioned by botanical origin. In Chile, the native flora is diverse and promising in terms of bioactive compounds, but many plants grow in metal-polluted areas. The associated bioaccumulation could negatively affect the antioxidant/antiradical abilities of bee pollen. To assess the relationship between the bioaccumulation of metals and the antioxidant activity of pollen, complete bee pollen was collected near and far from the Llaima Volcano, albeit in ranges that ensured the same botanical origins. Mellisopalynological analysis determined Escallonia rubra pollen was the most abundant native flora in complete bee pollen. Therefore, E. rubra pollen collected near and far from the Llaima Volcano was evaluated for the following: phenolic compounds via colorimetric assays; antioxidant activity via ferric reducing/antioxidant power assays; antiradical activity via 1,1-diphenyl-2-picrylhydrazyl radical assays; and metal contents via inductively coupled plasma optical emission spectrometry. Llaima samples had higher $\mathrm{Cu}$ and $\mathrm{Fe}$ but lower $\mathrm{Mn}$ contents and lower antioxidant and antiradical capacities than did the control samples. These results were
\end{abstract}


supported by subsequent fortification assays in Llaima E. rubra samples. In fortified samples with significantly higher metal contents, antiradical and antioxidant abilities decreased. Moreover, shifts in migration times were found for naringenin, rutine, and caffeic acid after capillary electrophoresis (CE) analysis in fortified samples. In conclusion, the results indicated an inverse correlation between metal contents and antioxidant/antiradical potentials in bee pollen.

Keywords: Antioxidant, antiradical activity, capillary electrophoresis, metals, phenol

\section{Introduction}

Bee pollen is a conglomerate of plant pollen that is combined in the corbicula, a special cavity on the hind legs in honeybees (Apis mellifera) (Montenegro et al., 2013). The quantity of water in bee pollen varies between 4 and 10\%, and this water content ensures good preservation over time and the nondegradation of organic compounds, which consequently maintain original inherent properties (Gergen et al., 2006; Nogueira et al., 2012). The chemical composition of bee pollen varies according to the plant origin, geographical location, and environmental conditions (Komosinska-Vassev et al., 2015; Nogueira et al., 2012). Despite the variations, bee pollen is normally acidic, with a $\mathrm{pH}$ between 3.4 and 5.1, and composed of $20 \%$ proteins (including essential amino acids), 55\% total carbohydrates with $25 \%$ reducing sugars (primarily fructose and glucose), 5\% lipids, $1.6 \%$ phenolic compounds, $0.7 \%$ vitamins, and $1.6 \%$ bioelements (macro and micronutrients) (Campos et al., 2008; Komosinska-Vassev et al., 2015; Nogueira et al., 2012). Of the metals, the most predominant are iron, magnesium, manganese, copper, zinc, calcium, sodium, and potassium (Vit and Santiago, 2008). Considering this diverse composition, bee pollen is a nutritional supplement with a variety of properties that can be determined from the chemical nature of the compounds within bee pollen (Taha, 2015; Yang et al., 2013). One important group of compounds is polyphenols, which are directly related to the antioxidant capacity of several bee pollens (Denisow and Denisow-Pietrzyk, 2016).

The three most important groups of compounds with antioxidant properties in bee pollen are flavonoids, phenolic acids, and tannins (Mărghitaş et al., 2009; Pascoal et al., 2014). The mechanisms of antiradical activity are different according to the chemical structure of each compound (Denisow and Denisow-Pietrzyk, 2016). In bee pollen, these compounds act together as antioxidants, with each contributing toward the total activity (Almaraz-Abarca $e t$ al., 2007; LeBlanc et al., 2009; Leja et al., 2007; Rzepecka-Stojko et al., 2015). Usually, the 
total polyphenol content, antioxidant activity, and antiradical activity are related to the physiological and bioactive roles of substances in terms of human nutrition (Kroyer and Hegedus, 2001).

The chemical profiles of natural extracts obtained from a complex organic matrix, such as pollen or honey, have traditionally been determined through chromatographic techniques (e.g., HPLC, FTIR, HPLC-UV, and HPLC-MS) (Dominguez et al., 2016; Liang et al., 2016). Nevertheless, capillary electrophoresis (CE) and related techniques, such as electrokinetic chromatography, are interesting alternatives because they possess several advantages, including decreased analysis time, high separation efficiency, ultra-small sample volume, and low reagent consumption (Arráez-Román et al., 2006; Moreno-González et al., 2015; Nicolaou and Kapnissi-Christodoulou, 2010; Rizelio et al., 2012).

Several apiculture products, such as honey, pollen, and propolis, are suitable materials for monitoring environmental contamination (Formicki et al., 2013; González-Martín et al., 2015). This attribute is due to the direct contact that honeybees have with environmental contaminants during flight and through food sources (e.g., plant pollen, nectar, and water) (Lambert et al., 2012; Przybyl-owski and Wilczyńska, 2001). Because the botanical origin is the primary conditioner for the composition of apiculture products, any contaminating compounds can likely be traced to the originating plant species (Almeida-Muradian et al., 2005; Campos et al., 2008). Several studies have assessed contaminants in honeys, including antibiotics (Al-Waili, et al., 2012), heavy metals (Fredes and Montenegro, 2006; Tuzen et al., 2007), pesticides (Panseri et al., 2014; Rodríguez López et al., 2014), and others (CortopassiLaurino et al., 2006; Lambert et al., 2012). Volcanic activity can also affect the mineral composition of honeys and pollens produced in nearby areas (Mejías and Montenegro, 2012). Despite these links, pollen is an understudied apiculture product in terms of its chemical composition, biological activity, and possible contaminants.

The aim of this study was to assess the relationship between bioaccumulation of metals and the effect on the antioxidant activity of native pollen samples. The first step determined the botanical origins of bee pollen collected in an area affected by volcanic activity and consequently metal pollution. Immediately after this determination, the most predominant Chilean native species detected in the assessed bee pollen was isolated and subsequently evaluated via $\mathrm{CE}$ and mass spectrophotometry to determine the phenolic contents. The selected native samples were also fortified by aliquots of certified reference materials for lead $(\mathrm{Pb})$, cadmium $(\mathrm{Cd})$, and chromium $(\mathrm{Cr})$. Electropherograms from the fortified and control 
groups were then compared to established behavioral differences in phenolic compounds as a result of increased metal presence.

\section{Materials and methods}

Pollen samples

Pollen samples were collected near the town of Vilcún in the Araucanía Region of southern Chile (38 $41^{\prime} 59.80^{\prime \prime}$ S, $71^{\circ} 45^{\prime} 22.70^{\prime}$ 'W). Samples were obtained near or distant from (>30 $\mathrm{km}$ ) the Llaima Volcano, with these samples constituting the Llaima and control groups, respectively. Importantly, both collection areas contained the same botanical species. Complete bee pollen samples were collected from five beehives located in each sampling zone.

\section{Mellisopalynological analysis for determining the botanical origin of bee pollen}

The botanical composition of bee pollen samples was quantitatively counted following methods described by Louveaux et al. (1978). Briefly, bee pollen (20 g) was placed on acetolyzed slides (Montenegro et al., 2008). Then, a sample aliquot was diluted with warm distilled water $\left(20 \mathrm{~mL}\right.$ at $\left.40{ }^{\circ} \mathrm{C}\right)$, and the solution was transferred to an appropriate tube and centrifuged at 3,500 rpm for $10 \mathrm{~min}$. The supernatant was discarded, and the pollen residue was deposited at the bottom of the tube for re-suspension in distilled water $(100 \mathrm{~mL})$. An aliquot $(20 \mathrm{~mL})$ was then added to a slide with Calberla's solution $(10 \mathrm{~mL})$, which was either basic fuchsine or diamond. The slide was gently dried. Finally, melted glycerinated gelatin $(15 \mathrm{~mL})$ was added to the mixture. For each sample, pollen grain residues were identified using an optical microscope at 400X and 1000X magnifications. Both the Llaima and control samples were analyzed using the above criteria.

\section{Preparation of E. rubra pollen solutions}

Mellisopalynological analysis revealed Escallonia rubra to be a primary component (45\%, Table 1) of the collected bee pollen samples. This species belongs to the native endemic flora of Chile and in this case, was the primary native component of the selected bee pollen samples Therefore, E. rubra pollen was isolated from every collected pollen sample and solutions prepared for subsequent colorimetric, ferric reducing/antioxidant power (FRAP), 1,1-diphenyl-2-picrylhydrazyl radical (DPPH), metal content, and CE assays. Specifically, E. rubra pollen $(2 \mathrm{~g})$ was suspended in distilled water $(4.0 \mathrm{~mL}, \mathrm{pH} 4)$ and then vortexed. The $\mathrm{pH}$ range for all suspensions was between $\mathrm{pH} 4.8$ and 5.5. 


\section{Colorimetric assays for determining Total Phenolic Compounds}

The procedures described by Singleton and Rossi (1965) and Buratti et al. (2007) were used with minor modifications. Briefly, E. rubra pollen solution $(200 \mu \mathrm{L})$ was mixed with the Folin-Ciocalteu reagent $(50 \mu \mathrm{L})$ and $20 \% \mathrm{Na} 2 \mathrm{CO} 3(150 \mu \mathrm{L})$. Finally, distilled water $(600 \mu \mathrm{L})$ was added. Absorbance at $765 \mathrm{~nm}$ was determined after $30 \mathrm{~min}$ in a Shimadzu (Brazil) UV1700 UV-visible spectrophotometer. Gallic acid was used as the standard to derive the calibration curve (0-150 mg mL-1). The results revealed the phenolic contents of E. rubra pollen (expressed as the mg equivalent of gallic acid $\mathrm{kg}-1$ of sample). All samples were analyzed in triplicate.

\section{FRAP assays for determining antioxidant activity}

FRAP assays were performed according to Bertoncelj et al. (2007). Briefly, the FRAP reagent was prepared by mixing $2.5 \mathrm{~mL}$ of 2,4,6-tripyridyls-triazine (TPTZ; $10 \mathrm{mM}$ TPTZ $40 \mathrm{mM}-1$ $\mathrm{HCl})$ with $2.5 \mathrm{~mL}$ of $20 \mathrm{mM} \mathrm{FeCl} 3$. Then, $0.3 \mathrm{M}$ acetate buffer $(25.0 \mathrm{~mL}, \mathrm{pH} 3.6)$ was added to the mixture. The FRAP reagent was freshly prepared for each assay run. To measure antioxidant capacity, E. rubra pollen $(0.200 \mathrm{~mL})$ was mixed with the FRAP reagent $(1.8 \mathrm{~mL})$. Absorbance was read at $593 \mathrm{~nm}$ after $10 \mathrm{~min}$. FeSO4•7H2O was used as the standard to derive the calibration curve (50-1000 mM). The values are expressed as $\mathrm{mM} \mathrm{Fe}+2$ equivalents g-1 of sample. Samples were analyzed in triplicate.

\section{DPPH assays for determining antiradical activity}

The procedures described by Meda et al. (2005), as modified by Mejías and Montenegro (2012), were used to determine antiradical activity. The DPPH assay establishes the antiradical properties of the chemical compounds in pollen by inhibiting or decreasing the oxidant activity of DPPH. Briefly, E. rubra extracts $(750 \mu \mathrm{L})$ were mixed with the DPPH radical $(1.5 \mathrm{~mL})$ in methanol $(0.02 \mathrm{mg}$ DPPH mL-1 MeOH). Absorbance was read at $517 \mathrm{~nm}$ after 15 min. A blank sample was prepared with methanol. Ascorbic acid (Calbiochem, Germany) was used as the standard to derive the calibration curve (1-10 mg mL-1). The values for antiradical activity are expressed as mg of ascorbic acid equivalents/g of sample. Samples were analyzed in triplicate.

\section{Determining metal contents}


Heavy metal contents in E. rubra pollen samples were determined following protocols defined in the Chilean standard (INN, 2008). Briefly, E. rubra pollen (5 g) was placed in a porcelain crucible that was subsequently placed in a muffle furnace for $3 \mathrm{~h}$ at $105{ }^{\circ} \mathrm{C}$. Subsequently, the temperature of the muffle oven was gradually increased to $130{ }^{\circ} \mathrm{C}$, with samples kept at this temperature for $12 \mathrm{~h}$. Then, the samples were digested by $65 \%$ HNO3 and in the crucible, placed on a heating plate at $50{ }^{\circ} \mathrm{C}$ for $30 \mathrm{~min}$. Subsequently, aliquots of acid $(2 \mathrm{~mL})$ were added to prevent boiling. The aliquots were added until achieving total dissolution of the sample or the absolute disappearance of turbidity inside the crucible. The excess acid was evaporated until the sample was completely dried. Finally, the residue in the crucible was resuspended in $2 \% \mathrm{HNO} 3(10 \mathrm{~mL})$, and the resulting solution was fully transferred to a volumetric flask $(10 \mathrm{~mL})$ for further readings via inductively coupled plasma optical emission spectrometry.

\section{Fortification assays}

Escallonia rubra pollen samples were fortified using the certified reference material CMRCMQ- FCHILE-007 lot No. 012 bottle No. 006. The manufacturer reported concentrations of this material as follow: $\mathrm{Pb} 49 \mu \mathrm{g} \mathrm{L}-1, \mathrm{Cr} 36 \mu \mathrm{g} \mathrm{L}-1$ and Cd $32 \mu \mathrm{g} \mathrm{L}-1$. Escallonia rubra pollen samples collected near the Llaima Volcano were fortified in increasing order of concentration with certified reference material aliquots of $\mathrm{Pb}, \mathrm{Cr}$, and $\mathrm{Cd}$. For this fortification, the pollen samples were separated into five subsample groups (termed A1, B1, C1, D1, and E1), each containing $500 \mathrm{mg}$ of pollen. The A1-D1 subsample groups received certified reference material aliquots, with the weights recorded to establish the final concentration for each metal in $\mu \mathrm{g} \mathrm{kg-1.} \mathrm{The} \mathrm{E1} \mathrm{group} \mathrm{was} \mathrm{not} \mathrm{fortified} \mathrm{and} \mathrm{was} \mathrm{used} \mathrm{as} \mathrm{the}$ control sample.

\section{Capillary electrophoresis with diode-array detection for determining phenolic contents}

Capillary electrophoresis with diode-array detection (CE-DAD) experiments were performed at the Laboratoire de Physicochimie des Electrolytes, Colloides et Sciences Analytiques (PECSA)-Chimie ParisTech (École Nationale Supérieure de Chimie de Paris). Specifically, an Agilent G1600A Capillary Electrophoresis System equipped with an on-column diode-array detection system was used. Instrument conditions were set according to Nicolaou and Kapnissi-Christodoulou (2010). Briefly, the fused silica capillaries had internal diameters of $50 \mu \mathrm{m}$, a total length of $64 \mathrm{~cm}$, and an effective length of $55 \mathrm{~cm}$. New capillaries were rinsed with water for $10 \mathrm{~min}$, followed by $1 \mathrm{M} \mathrm{NaOH}$ for $1 \mathrm{~h}$, water again for $20 \mathrm{~min}$, and finally a 
background electrolyte (i.e., $0.1 \mathrm{M}$ sodium tetraborate decahydrate) for $15 \mathrm{~min}$. Samples were injected by applying a pressure of 50 mbar for $5 \mathrm{~s}$. The separation voltage was $25 \mathrm{kV}$.

\section{Statistical analyses}

Exploratory data analyses were performed to evaluate patterns, detect anomalous values, and verify assumptions of statistical tests, including normality, independence, and homoscedasticity. Differences in phenol contents, antioxidant activity, and FRAP values between Llaima and control samples were established via one-way ANOVA with a post hoc Tukey's test.

\section{Results}

\section{Botanical origin of bee pollen}

Mellisopalynological analysis was used to separate and identify the distinct plant pollens in complete bee pollen collected near the Llaima Volcano (Table 1). Based on the results, the most abundant native pollen was that of E. rubra, which was chosen for subsequent determinations of antioxidant properties and phenolic compound profiles via CE.

\begin{tabular}{lc}
$\begin{array}{l}\text { Table 1. Abundance estimations for different plant } \\
\text { species in bee pollen samples collected near the Llaima } \\
\text { Volcano. }\end{array}$ \\
\hline Botanical origin & Amount (\%) \\
\hline Lotus uliginosus & 52 \\
Escallonia rubra & $45^{\dagger}$ \\
Trifolium repens & 1 \\
Embothrium coccineum & $<1$ \\
Rubus sp. & $<1$ \\
\hline
\end{tabular}

${ }^{\dagger}$ As a native plant species and primary component of the total bee pollen sample, E. rubra was used in subsequent pollen analyses.

\section{Composition of Total Phenolic Compounds of E. rubra pollen}

Colorimetric analyses using the Folin-Ciocalteu reagent revealed no statistically significant differences in total hydrosoluble phenolic compounds between Llaima and control samples (Table 2). However, the control samples had 32\% and 25\% higher antioxidant and antiradical capacities, respectively, than did the samples collected near the Llaima Volcano (Table 2). 
Table 2. Chemical analysis of E. rubra pollen collected near (Llaima-experimental) and distant from (control) the Llaima Volcano.

\begin{tabular}{lccc}
\hline $\begin{array}{l}\text { Bee pollen } \\
\text { sample }\end{array}$ & $\begin{array}{c}\text { Phenols } \\
\left(\mathrm{mg} \mathrm{kg}^{-1}\right)\end{array}$ & $\begin{array}{c}\text { FRAP } \\
\left(\mathrm{mM} \mathrm{g}^{-1}\right)\end{array}$ & $\begin{array}{c}\text { DPPH } \\
\left(\mu \mathrm{g} \mathrm{g}^{-1}\right)\end{array}$ \\
\hline Llaima & $2480.83 \pm 1.2 \mathrm{a}$ & $61.3 \pm 0.8 \mathrm{~b}$ & $291.2 \pm 0.88 \mathrm{~b}$ \\
Control & $2410.82 \pm 2.4 \mathrm{a}$ & $90.4 \pm 0.9 \mathrm{a}$ & $321.6 \pm 1.01 \mathrm{a}$ \\
\hline
\end{tabular}

All values represent the mean $\pm \mathrm{SD}$ for the Llaima $(\mathrm{n}=10)$ and control $(\mathrm{n}=5)$ samples. Different letters within columns indicate significant differences (Tukey's test, $\mathrm{P}<0.05$ ). DPPH, 1,1-diphenyl-2-picrylhydrazyl radical; FRAP, ferric reducing/ antioxidant power.

Metal contents of $\mathrm{E}$. rubra pollen

Metal content analyses revealed no significant differences between Llaima and control samples in terms of their $\mathrm{Zn}$ and $\mathrm{Cr}$ concentrations. However, the concentrations of $\mathrm{Cu}, \mathrm{Fe}$, $\mathrm{Pb}$, and $\mathrm{Cd}$ were higher in Llaima samples, but the $\mathrm{Mn}$ concentrations were significantly lower in the Llaima samples than they were in their control counterparts (Table 3).

\begin{tabular}{|c|c|c|}
\hline \multirow{2}{*}{ Mineral } & \multicolumn{2}{|c|}{ Bee pollen samples ( $\left.\mathrm{mg} \mathrm{kg}^{-1}\right)$} \\
\hline & Llaima & Control \\
\hline $\mathrm{Cu}$ & $10.7 \pm 0.7 \mathrm{a}$ & $8.8 \pm 0.2 b$ \\
\hline $\mathrm{Zn}$ & $82.3 \pm 2.4 \mathrm{a}$ & $86.6 \pm 0.2 \mathrm{a}$ \\
\hline $\mathrm{Mn}$ & $42.5 \pm 2.9 \mathrm{~b}$ & $62.9 \pm 0.3 \mathrm{a}$ \\
\hline $\mathrm{Fe}$ & $76.5 \pm 0.3 \mathrm{a}$ & $42.7 \pm 1.4 \mathrm{~b}$ \\
\hline $\mathrm{Pb}$ & $0.02 \pm 0.002 \mathrm{a}$ & $0.03 \pm 0.001 \mathrm{a}$ \\
\hline $\mathrm{Cd}$ & $0.02 \pm 0.01 \mathrm{a}$ & $0.03 \pm 0.01 \mathrm{a}$ \\
\hline $\mathrm{Cr}$ & $0.03 \pm 0.05 a$ & $0.03 \pm 0.01 \mathrm{a}$ \\
\hline
\end{tabular}

\section{Effects of fortification on the composition of}

\section{Total Phenolic Compounds of E. rubra pollen}

Four subsample groups (i.e., A1-D1) of E. rubra pollen collected near the Llaima Volcano were fortified with increasing amounts of certified reference material for $\mathrm{Pb}, \mathrm{Cd}$, and $\mathrm{Cr}$. $\mathrm{An}$ additional subsample (i.e., E1) was left unfortified and used as the control. Compared with the E1 control, the final metal concentrations in the least (i.e., A1) and most (i.e., D1) fortified 
subsamples were as follow: A1 subsample: 177 times more $\mathrm{Pb}, 805$ times more $\mathrm{Cr}$, and 99 times more $\mathrm{Cd}$; and $\mathrm{D} 1$ subsample, 705 times more $\mathrm{Pb}, 3220$ times more $\mathrm{Cr}$, and 392 times more Cd. In other words, the D1 subsample presented four times higher metal contents than the A1 subsample. The fortification results for all subsample groups are presented in Table 4.

Table 4. Final $\mathrm{Pb}, \mathrm{Cd}$, and $\mathrm{Cr}$ concentrations after the fortification of E. rubra pollen subsamples (A1-D1). The subsample group E1 was not fortified and was used as the control.

\begin{tabular}{lcccc}
\hline & & \multicolumn{3}{l}{$\begin{array}{l}\text { Final concentration }\left(\mu \mathrm{kg}^{-1}\right) \\
\left(\mathrm{mg} \mathrm{kg}^{-1} \text { E. rubra pollen }\right)\end{array}$} \\
\cline { 3 - 5 } Sample & $\begin{array}{l}\text { E. rubra } \\
\text { pollen }(\mathrm{g})\end{array}$ & $\mathrm{Pb}$ & $\mathrm{Cd}$ & $\mathrm{Cr}$ \\
\hline $\mathrm{A} 1$ & 0.498 & 49.5 & 32.2 & 36.5 \\
$\mathrm{~B} 1$ & 0.535 & 91.8 & 59.8 & 67.7 \\
$\mathrm{C} 1$ & 0.503 & 146.3 & 95.4 & 107.7 \\
$\mathrm{D} 1$ & 0.497 & 197.3 & 128.8 & 145.2 \\
E1 & 0.959 & 23.0 & 21.0 & 30.0 \\
\hline
\end{tabular}

No relationship was found between total phenolic compounds and fortification in the distinct subsample groups. In evaluating the linear relationship, the R2 value was 0.1657 (Fig. 1).

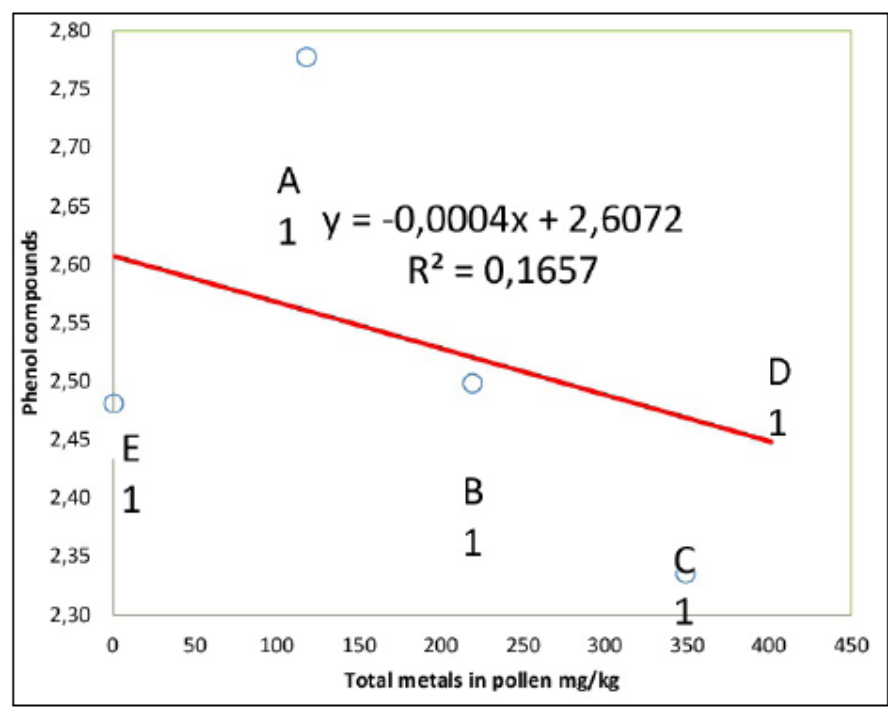

Figure 1. Relationship between total phenolic compounds and the final concentration of metals in E.rubra pollen samples after fortification.

The fortified samples of E. rubra pollen were also evaluated to determine their antioxidant and antiradical capacities. Relationship assessments between final metal concentrations and 
antioxidant capacity (Fig. 2) revealed an exponential tendency, with an adjustment of 0.9343 . Therefore, as metal concentrations increased, the antioxidant capacity of pollen subsamples decreased. Similarly, increased metal concentrations were correlated with decreased antiradical capacity (Fig. 3), with an exponential tendency presenting an adjustment of 0.9689 .

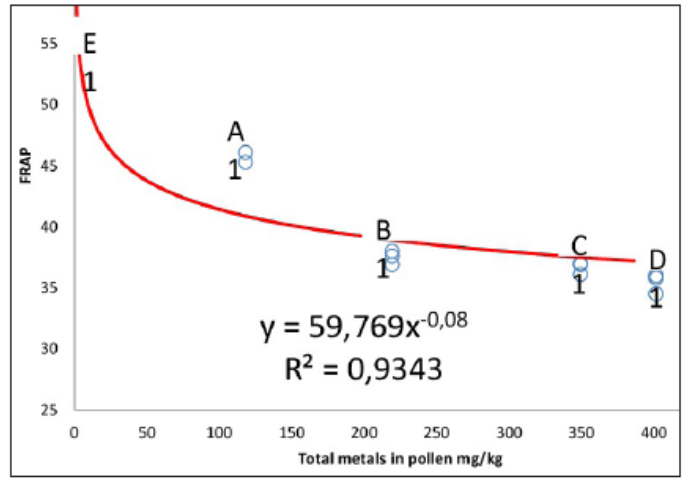

Figure 2. Relationship of final metal concentrations (i.e., post-fortification) in E. rubra pollen with antioxidant activity, measured through ferric reducing/antioxidant power (FRAP).

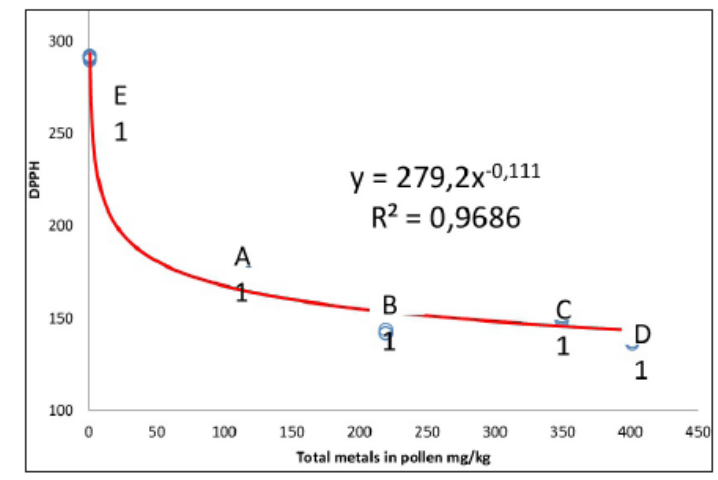

Figure 3. Relationship of final metal concentrations (i.e. post-fortification) in E. rubra pollen with antiradical activity, measured through the 1,1-diphenyl-2picrylhydrazyl radical (DPPH).

\section{Effects of fortification on phenolic profiles in E. rubra pollen}

Using CE-DAD analysis, changes in the phenolic profiles of fortified E. rubra subsamples were detected (Table 5). The migration times of the distinct evaluated standards were displaced, specifically for naringenin, rutine, p-coumaric acid, ferulic acid, caffeic acid, and gallic acid.

Table 5. Migration time of the phenolic profile for naringenin, rutine, p-coumaric acid, ferulic acid, caffeic acid, and gallic acid in E. rubra subsamples after fortification, as determined through capillary electrophoresis with diode-array detection. (A-E): non-fortified (E) and increasingly fortified from A to D.

\begin{tabular}{lccccc}
\hline & \multicolumn{5}{c}{ Migration time (min.) } \\
\cline { 2 - 6 } Compound & $\mathrm{A}$ & $\mathrm{B}$ & $\mathrm{C}$ & $\mathrm{D}$ & Control \\
\cline { 2 - 6 } & 6.213 & 7.316 & 8.008 & 8.011 & $\mathrm{E}$ \\
\hline Naringenin & 6.977 & 7.461 & 8.471 & 8.703 & 6.273 \\
Rutine & 8.660 & 9.261 & 10.210 & 10.362 & 8.002 \\
p-Coumaric acid & 8.889 & 9.509 & 10.787 & 11.929 & 8.177 \\
Ferulic acid & 11.189 & 12.132 & 12.932 & 13.822 & 9.858 \\
Caffeic acid & 11.347 & 12.581 & 13.468 & 14.141 & 9.987 \\
Gallic acid & & & & & \\
\hline
\end{tabular}




\section{Discussion}

Species from the Escallonia family include small trees and bushes primarily distributed in mountainous and humid regions, with a range from Costa Rica to Tierra del Fuego in Argentina and Chile. Nevertheless, most Escallonia species are located within Andean zones in Argentina, Chile, and Peru (Morello et al., 2013). This family is widely reported between the $30^{\circ}$ and $53^{\circ}$ latitudes, which would account for the high prevalence of E. rubra pollen in the collected bee pollen samples (Table 1). Escallonia rubra pollen has also been reported in other nectar and honey samples collected from Andean zones in South America (Chalcoff et al., 2006; Mejías and Montenegro, 2012; Montenegro et al., 2010).

Heavy metals are elements with a relative density higher than the density of water (Tchounwou et al., 2012). Some of these elements are considered micronutrients, but others, such as lead, cadmium, chromium, and mercury, can be toxic to plants at high levels of concentration, which are unable to metabolize these elements (Michalak, 2006). The primary toxic effects of heavy metals result from the production of reactive oxygen species and reactive nitrogen species (Bhaduri and Fulekar, 2012; Sytar et al., 2013). At a cellular level, heavy metals inhibit antioxidant enzymes, damage DNA, oxidize proteins and lipids, and cause a redox imbalance, among other effects (Nagajyoti et al., 2010; Tchounwou et al., 2012). Two types of cellular mechanisms are used to confront these negative effects. First, mechanisms using enzymes, such as superoxide dismutase, catalases, peroxidases, and reductases, are activated. Second, non-enzymatic mechanisms are used, which include some vitamins (e.g., A, E, and D), amino acids (e.g., proline), and carotenoids and flavonoids (Gill and Tuteja, 2010).

Chemical analysis of E. rubra pollen revealed that although the concentrations of total phenolic compounds were similar between Llaima and control samples, antioxidant and antiradical activities were lower in pollen samples collected near the Llaima Volcano (Table 2). Furthermore, Llaima samples also showed higher concentrations of heavy metals, including copper, iron, lead, and cadmium (Table 3). Antioxidant potential can also be predicted by the availability of phenolic and flavonoid compounds, which donate hydrogen radicals that neutralize free radicals (Buratti et al., 2007). Heavy metal contamination originates from various sources, including industrial, agricultural (pesticides), domestic (wastewater), atmospheric, and natural (volcanoes) sources (Nagajyoti et al., 2010). Nonetheless, the metals in bee products are related to the botanical origin, which depends on the geographical origin and the composition of soils in the areas surrounding beehives (Bilandzic et al., 2017). 
To determine whether the decreased antioxidant activity in the pollen samples was effectively due to the high heavy metal concentrations, fortification assays were performed with increasing amounts of certified reference materials in E. rubra pollen subsamples (Table 4). The previously observed pattern was effectively maintained: total phenol concentrations were the same between subsamples, but antioxidant and antiradical activities decreased exponentially as heavy metal concentrations increased (Figs. 2 and 3). These results were further corroborated via CE-DAD, which revealed changes in the phenolic profile as a result of variation in migration times for the distinct applied standards (Table 5). A plausible reason for the shift in migration times of pollen polyphenols in the metal-fortified samples might be complex formation between polyphenols and metals. Polyphenols are well known for their ability to chelate heavy metals such as $\mathrm{Fe}, \mathrm{Pb}$, and $\mathrm{Cu}$. By chelating heavy metals, polyphenols prevent free radical formation (antioxidant effect) by a possible Fenton-like reaction. Interaction of heavy metals with polyphenols/flavonoids involves the same hydroxyl groups that are involved in the FRAP or DPPH antioxidant assays. Complexation of these groups by metal ions renders them unavailable for hydrogen transfer from the phenolic $\mathrm{OH}$ group (followed by an electron transfer) in these assays, which is then observed as a decrease in antioxidant capability (Bautista et al., 2008; Mahal et al., 2005).

Crane (1984) was the first to propose using apiculture products as biomarkers for environmental contamination. Honeybees can be used to identify chemical disruptions in the environment via two signals: hive death and detection of residues of contaminated substances in apiculture products (Bargańska et al., 2016). A highly notable advantage in using apiculture products as biomarkers is the early and spatial detection of patterns for distinct environmental contaminants (Van Der Steen et al., 2015). This strategy is founded on the fact that botanical origin is the primary conditioner for the chemical composition of apiculture products. Therefore, the plant species of origin dictates the presence of antioxidant compounds and subsequent bioactive traits, in addition to contaminants such as pesticides and heavy metals (Almeida-Muradian et al., 2005; Campos et al., 2008). Various studies exemplify the use of apiculture biomarkers in the detection of heavy metals (i.e., lead, cadmium, chromium, and nickel), pesticides, and other anthropogenic environmental contaminants, including aromatic hydrocarbons, perfluorinated compounds, and phthalates (Formicki et al., 2013; Gómez-Ramos et al., 2016; Porrini et al., 2003; Tuzen et al., 2007; Üren et al., 1998).

The effects of contaminants on human health are a growing concern. Although some elements are required in low doses to maintain biological functions, chronic exposure, even at low 
doses, can cause functional damage to distinct organs. This damage is in addition to the associations of exposure with diseases such as cancer, Parkinson's, and Alzheimer's (Jaishankar et al., 2014). Plants absorb heavy metals and other contaminants from a contaminated environment; however, because plants are unable to metabolize metabolize these compounds, bioaccumulation occurs (Liu et al., 2013; Michalak, 2006). Given that plants are one of the primary food sources for humans, heavy metal exposure through plants accounts for $90 \%$ of total metal intake, with only $10 \%$ occurring via dermal contact or inhalation (Khan et al., 2015).

The results of this study establish a foundation for future studies on bee pollen and other apiculture products. Continued research in this field is critical, because these products can be applied as a useful tool for studying the environmental effects of anthropogenic contamination, with the data collected used to aid in developing efficient monitoring and control protocols.

\section{Disclosure statement}

No potential conflict of interest was reported by the authors.

\section{Acknowledgements}

This work was supported by the Office of the Vice-Rector for Academic Affairs, Universidad Tecnológica Metropolitana under Grant VRACUTEM L216-11, awarded to Dr. Enrique Mejías.

\section{References}

Al-Waili, N., K. Salom, A. Al-Ghamdi, and M. J. Ansari. 2012. Antibiotic, pesticide, and microbial contaminants of honey: human health hazards. The Scientific World Journal, 2012:1-9.

Almaraz-Abarca, N., M. da Graça Campos, J.A. Ávila-Reyes, N. Naranjo-Jiménez, J. Herrera Corral, and L.S. González-Valdez. 2007. Antioxidant activity of polyphenolic extract of monofloral honeybee-collected pollen from mesquite (Prosopis juliflora, Leguminosae). J Food Compost Anal 20(2):119-124. 
Almeida-Muradian, L.B., L.C. Pamplona, S. Coimbra, and O.M. Barth. 2005. Chemical composition and botanical evaluation of dried bee pollen pellets. Food Compost Anal 18(1):105-111.

Arráez-Román, D., A.M. Gómez-Caravaca, M. Gómez-Romero, A. Segura-Carretero, and A. Fernández-Gutiérrez. 2006. Identification of phenolic compounds in rosemary honey using solid-phase extraction by capillary electrophoresis-electrospray ionization-mass spectrometry. J Pharm Biomed Anal 41(5):1648-1656.

Bargańska, Ż., M. Ślebioda, and J. Namieśnik. 2016. Honey bees and their products: Bioindicators of environmental contamination. Crit Rev Environ Sci Technol 46(3):235-248.

Bautista, P., A.F. Mohedano, J.A. Casas, J.A. Zazo, and J.J. Rodriguez. 2008. An overview of the application of Fenton oxidation to industrial wastewaters treatment. J Chem Technol Biotechnol 83:1323-1338.

Bertoncelj, J., U. Doberšek, M. Jamnik, and T. Golob. 2007. Evaluation of the phenolic content, antioxidant activity and colour of Slovenian honey. Food Chem 105(2):822-828.

Bhaduri, A.M., and M.H. Fulekar. 2012. Antioxidant enzyme responses of plants to heavy metal stress. Rev. Environ. Sci. Biotechnol. 11(1):55-69.

Bilandzic, N., I. Tlak Gajger, M. Kosanovic, et al. 2017 Essential and toxic element concentrations in monofloral honeys from southern Croatia. Food Chem 234:245-253.

Buratti, S., S. Benedetti, and M.S. Cosio. 2007. Evaluation of the antioxidant power of honey, propolis and royal jelly by amperometric flow injection analysis. Talanta 71(3):1387-1392.

Campos, M.G.R., S. Bogdanov, L. Bicudo De Almeida-Muradian, T. Szczesna, Y. Mancebo, C. Frigerio, and F. Ferreira. (2008). Pollen composition and standardization of analytical methods. Journal of Apicultural Research and Bee World 47(2):156-163.

Chalcoff, V.R., M.A. Aizen, and L. Galetto. 2006. Nectar concentration and composition of 26 species from the temperate forest of South America. Ann. Bot. 97(3):413-421. 
Cortopassi-Laurino, M., V.L. Imperatriz-Fonseca, D. Ward Roubik, A. Dollin, T. Heard, I. Aguilar, and P. Nogueira-Neto. 2006. Global meliponiculture: challenges and opportunities. Apidologie 37:275-292.

Crane, E. 1984. Bees, honey and pollen as indicators of metals in the environment. Bee World 65(1):47-49.

Denisow, B., and M. Denisow-Pietrzyk. 2016. Biological and therapeutic properties of bee pollen: a review. J. Sci. Food Agric. 96(13):4303-4309.

Dominguez, M.A., J. Jacksén, A. Emmer, and M.E. Centurión. 2016. Capillary electrophoresis method for the simultaneous determination of carbohydrates and proline in honey samples. Microchem J 129:1-4.

Formicki, G., A. Gren, R. Stawaez, B. Zysk, and A. Gal. 2013. Metal content in honey, propolis, wax, and bee pollen and implication for metal pollution monitoring. Pol J Environ Stud 22(1):99-106.

Fredes, C., and G. Montenegro. 2006. Heavy metal and other trace elements contents in honey bee in Chile. Cien. Inv. Agr. 33(1):50-58.

Gergen, I., F. Radu, D. Bordean, and H.D. Isengard. 2006. Determination of water content in bee's pollen samples by Karl Fischer titration. Food Control 17(3):176-179.

Gill, S.S., and N. Tuteja. 2010. Reactive oxygen species and antioxidant machinery in abiotic stress tolerance in crop plants. Plant Physiol. Biochem. 48(12):909-930.

Gómez-Ramos, M.M., A.I. García-Valcárcel, J.L. Tadeo, A.R. Fernández-Alba, and M.D Hernando. 2016. Screening of environmental contaminants in honey bee wax comb using gas chromatography-high-resolution time-of-flight mass spectrometry. Environmental Science and Pollution Research 23(5):4609-4620. 
González-Martín, M.I., O. Escuredo, I. Revilla, A.M. Vivar-Quintana, M. Carmen Coello, C.P. Riocerezo, and G.W. Moncada. 2015. Determination of the mineral composition and toxic element contents of propolis by near infrared spectroscopy. Sensors (Switzerland) 15(11): 27854-27868.

Jaishankar, M., T. Tseten, N. Anbalagan, B.B. Mathew, and K.N. Beeregowda. 2014. Toxicity, mechanism and health effects of some heavy metals. Interdiscip Toxicol 7(2):60-72.

Khan, A., S. Khan, M.A. Khan, Z. Qamar, and M. Waqas. 2015. The uptake and bioaccumulation of heavy metals by food plants, their effects on plants nutrients, and associated health risk: a review. Environmental Science and Pollution Research 22(18):13772-13799.

Komosinska-Vassev, K., P. Olczyk, J. Kaźmierczak, L. Mencner, and K. Olczyk. 2015. Bee pollen: Chemical composition and therapeutic application. Evid Based Complement Alternat Med 2015:1-6

Kroyer, G., and N. Hegedus. 2001. Evaluation of bioactive properties of pollen extracts as functional dietary food supplement. Innov Food Sci Emerg Technol. 2(3):171-174.

Lambert, O., M. Piroux, S. Puyo, C. Thorin, M. Larhantec, F. Delbac, and H. Pouliquen. 2012. Bees, honey and pollen as sentinels for lead environmental contamination. Environ. Pollut. 170:254-259.

Lambert, O., B. Veyrand, S. Durand, P. Marchand, B. Le Bizec, M. Piroux, and H. Pouliquen. 2012. Polycyclic aromatic hydrocarbons: Bees, honeyand pollen as sentinels for environmental chemical contaminants. Chemosphere 86(1):98-104.

LeBlanc, B.W., O.K. Davis, S. Boue, A. De Lucca, and T. Deeby. 2009. Antioxidant activity of Sonoran Desert bee pollen. Food Chem 115(4):1299-1305.

Leja, M., A. Mareczek, G. Wyzgolik, J. Klepacz-Baniak, and K. Czekońska. 2007. Antioxidative properties of bee pollen in selected plant species. Food Chem 100(1):237-240. 
Liang, P., M. Sun, P. He, L. Zhang, and G. Chen. 2016. Determination of carbohydrates in honey and milk by capillary electrophoresis in combination with graphene-cobalt microsphere hybrid paste electrodes. Food Chem 190:64-70.

Liu, X., Q. Song, Y. Tang, W. Li, J. Xu, J. Wu, and P.C. Brookes. 2013. Human health risk assessment of heavy metals in soil-vegetable system: A multi-medium analysis. Sci. Total Environ. 463-464:530-540.

Louveaux, J., A. Maurizio, and G. Vorwohl. 1978. Methods of melissopalynology. Bee World, 59(4):139-157.

Mahal, H., S. Kapoor, A. Satpati, and T. Mukherjee. 2005. Radical Scavenging and Catalytic Activity of Metal-Phenolic Complexes. J Phys Chem B 109(50):24197-24202.

Mărghitaş, L.A., O.G. Stanciu, D.S. Dezmirean, O. Bobiş, O. Popescu, S. Bogdanov, and M.G. Campos. 2009. In vitro antioxidant capacity of honeybee-collected pollen of selected floral origin harvested from Romania. Food Chem 115(3):878-883.

Meda, A., C.E. Lamien, M. Romito, J. Millogo, and O.G. Nacoulma. 2005. Determination of the total phenolic, flavonoid and proline contents in Burkina Fasan honey, as well as their radical scavenging activity. Food Chem 91(3):571-577.

Mejías, E., and G. Montenegro. 2012. The Antioxidant Activity of Chilean Honey and Bee Pollen Produced in the Llaima Volcano's Zones. J Food Qual 35(5):315-322.

Michalak, A. 2006. Phenolic Compounds and Their Antioxidant Activity in Plants Growing under Heavy Metal Stress. Plant Cell 15(4):523-530.

Montenegro, G., M. Gómez, J. Díaz-Forestier, and R. Pizarro. 2008. Aplicación de la Norma Chilena Oficial de denominación de origen botánico de la miel para la caracterización de la producción apícola. Cien. Inv. Agr. 35(2):181-190. 
Montenegro, G., R.C. Peña, and R. Pizarro. 2010. Multivariate analysis of pollen frequency of the native species Escallonia pulverulenta (Saxifragaceae) in Chilean honeys. Braz J Bot 33(4):615-630.

Montenegro, G., R. Pizarro, E. Mejias, and S. Rodriguez. 2013. Biological evaluation of bee pollen from native Chilean plants. Phyton (Buenos Aires) 82:7-14.

Morello, S., L.M. Giussani, and S.M. Sede. 2013. Análisis preliminar de la variabilidad genética de escallonia alpina y E. rubra (Escalloniaceae). Darwiniana 1(2):227-236.

Moreno-González, D., F.J. Lara, N. Jurgovská, L. Gámiz-Gracia, and A.M. García-Campaña. 2015. Determination of aminoglycosides in honey by capillary electrophoresis tandem mass spectrometry and extraction with molecularly imprinted polymers. Anal. Chim. Acta 891:321-328.

Nagajyoti, P.C., K.D. Lee, and T.V.M. Sreekanth. 2010. Heavy metals, occurrence and toxicity for plants: A review. Environ Chem Lett 8(3):199-216.

Nicolaou, I.N., and C.P. Kapnissi-Christodoulou. 2010. Analysis of polyphenols using capillary zone electrophoresis - Determination of the most effective wine sample pretreatment method. Electrophoresis 31(23-24):3895-3902.

Nogueira, C., A. Iglesias, X. Feás, and L.M. Estevinho. 2012. Commercial bee pollen with different geographical origins: A comprehensive approach. Int. J. Mol. Sci. 13(9):1117311187.

Panseri, S., A. Catalano, A. Giorgi, F. Arioli, A. Procopio, D. Britti, and L.M. Chiesa. 2014. Occurrence of pesticide residues in Italian honey from different areas in relation to its potential contamination sources. Food Control 38(1):150-156.

Pascoal, A., S. Rodrigues, A. Teixeira, X. Feás, and L.M. Estevinho. 2014. Biological activities of commercial bee pollens: Antimicrobial, antimutagenic, antioxidant and antiinflammatory. Food Chem. Toxicol. 63:233-239. 
Porrini, C., A.G. Sabatini, S. Girotti, S. Ghini, P. Medrzycki, F. Grillenzoni, and G. Celli. 2003. Honey Bees and Bee Products As Monitors of the Environmental Contamination. Apiacta 38(May 2017):63-70.

Przybyłowski, P., and A. Wilczyńska. 2001. Honey as an environmental marker. Food Chem 74(3):289-291.

Rizelio, V.M., L.V. Gonzaga, G.D.S.C. Borges, H.F. Maltez, A.C. Oliveira Costa, and R. Fett. 2012. Fast determination of cations in honey by capillary electrophoresis: A possible method for geographic origin discrimination. Talanta 99:450-456.

Rodríguez López, D., D.A. Ahumada, A.C. Díaz, and J.A. Guerrero. 2014. Evaluation of pesticide residues in honey from different geographic regions of Colombia. Food Control $37: 33-40$.

Rzepecka-Stojko, A., J. Stojko, A. Kurek-Gorecka, M. Gorecki, A. Kabala-Dzik, R. Kubina, and M. Iriti. 2015. Polyphenols from Bee Pollen: Structure, absorption, metabolism and biological activity. Molecules 20(12):21732-21749.

Singleton, V.L., and J.A.J Rossi. 1965. Colorunetry of total phenolics with phosphomolybdicphosphotungstic acid reagents. Am. J. Enology Vitic 16:144-158.

Sytar, O., A. Kumar, D. Latowski, P. Kuczynska, K. Strzalka, and M.N.V. Prasad. 2013. Heavy metal- induced oxidative damage, defense reactions, and detoxification mechanisms in plants. Acta Physiol. Plant. 35(4):985-999.

Taha, E.K.A. 2015. Chemical composition and amounts of mineral elements in honeybeecollected pollen in relation to botanical origin. J Apic Sci 59(1):75-81.

Tchounwou, P.B., C.G. Yedjou, A.K. Patlolla, and D.J. Sutton. 2012. Molecular, Clinical and Environmental Toxicology. In Molecular, Clinical and Environmental Toxicology. Volume 3: Environmental toxicology (Vol. 3, pp. 133-164). 
Tuzen, M., S. Silici, D. Mendil, and M. Soylak. 2007. Trace element levels in honeys from different regions of Turkey. Food Chem 103(2):325-330.

Üren, A., A. Şerifoglu, and Y. Sarikahya. 1998. Distribution of elements in honeys and effect of a thermoelectric power plant on the element contents. Food Chem 61(1-2):185-190.

Van Der Steen, J.J.M., J. De Kraker, and T. Grotenhuis. 2015. Assessment of the potential of honeybees (Apis mellifera L .) in biomonitoring of air pollution by cadmium, lead and vanadium. J Environ Prot 6:96-102.

Vit, P., and B. Santiago. 2008. Composición química de polen apícola fresco recolectado en el páramo de Misintá de los andes venezolanos. Arch Latinoam Nutr 58(4):411.

Yang, K., D. Wu, X. Ye, D. Liu, J. Chen, and P. Sun. 2013. Characterization of chemical composition of bee pollen in China. J. Agric. Food Chem. 61(3):708-718. 